\title{
An 'asymptomatic' driver with COVID-19: atypical suspected myocarditis by SARS-CoV-2
}

\author{
Wei-Feng Yuan ${ }^{1,2 \#}$, Xi Tang ${ }^{3 \#}$, Xin-Xiang Zhao ${ }^{1}$ \\ ${ }^{1}$ Department of Radiology, The Second Affiliated Hospital of Kunming Medical University, Kunming 650101, China; ${ }^{2}$ Department of Radiology, \\ ${ }^{3}$ Department of Medical Imaging, The First Affiliated Hospital of Chengdu Medical College, Chengdu 610500, China \\ \#These authors contributed equally to this work. \\ Correspondence to: Xin-Xiang Zhao, MD. Department of Radiology, The Second Affiliated Hospital of Kunming Medical University, The 374th \\ Dianmian Road, Wuhua District, Kunming 650101, China. Email: zhaoxinxiang0815@hotmail.com.
}

Submitted Feb 29, 2020. Accepted for publication Mar 10, 2020.

doi: $10.21037 /$ cdt.2020.03.08

View this article at: http://dx.doi.org/10.21037/cdt.2020.03.08

COVID-19 has become a global hotspot $(1,2)$. We report a case of COVID-19 with no sign of viral pneumonia but initially confirmed as myocarditis by SARS-CoV-2.

A 33-year-old-male Chinese taxi driver complained that he had contact history with a Wuhan resident on January 27, 2020. On February 5, he had chest pain, fever and muscle ache. His stool was normal. Further diagnosis and treatment were carried out in the fever clinic of our hospital on February 8. Physical examination after admission: body temperature $37.3^{\circ} \mathrm{C}$, pulse 121 times/min, breath 18 times/min, blood pressure 115/79 $\mathrm{mmHg}$. ECG indicated ventricular tachycardia. On February 8, CT scan of the chest was performed: there was no exact groundglass shadow in both lungs, a nodular calcification in the posterior segment of the upper lobe tip of the left lung near the mediastinum, and local thickening of the right pleura (Figure 1A,B). The above-mentioned chronic lesions were considered. SARS-CoV-2 nucleic acid was not detected in throat swab and EDTA anticoagulated whole blood on the same day, so viral pneumonia was not considered temporarily. On February 10, cardiac MRI was performed: the signal of T2WI in the apical region of the left ventricle was increased. After adjusting the parameters and scanning T2WI again, the signal was still increased (Figure 1C), indicating the possibility of myocardial cell edema; the signal of the corresponding segment was normal both in early gadolinium enhancement (EGE) (Figure 1D) and late gadolinium enhancement (LGE) (Figure 1E), indicating no obvious capillary leakage, myocardial necrosis or interstitial fibrosis. Left ventricular systolic function was slightly decreased (Figure $1 F$ ). Acute but atypical myocarditis was considered due to incompletely meeting Lake Louise Consensus Criteria (3). Due to subjective rejection and insufficient clinical evidence, the patient did not participate in endocardial biopsy. In order to confirm the diagnosis, urine and fecal samples were collected on the same day; no SARS-CoV-2 nucleic acid was detected in urine samples, but the two targets of SARS-CoV-2 in feces had typical S-type amplification curve (4). After consultation by the expert group, the diagnosis based on comprehensive diagnostic criteria (5) was: atypical COVID-19, myocarditis by SARS-CoV-2.

Could we assume that the virus stopped after invading the vascular endothelium and initiating inflammatory reaction, only causing cell degeneration and edema without necrosis? We doubt that Lake Louise Consensus Criteria might not be fully applicable to myocarditis by SARS-CoV-2? The patient was arranged to enter the isolation ward, but he questioned the diagnosis results. After persuasion, the patient agreed to reexamine the uric acid test (fecal samples were still positive, other samples were negative) on February 13 and cardiac MRI on February 22. The signal of T2WI mainly returned to normal, probably indicating myocarditis by SARS-CoV-2 has fairly good prognosis? We suggest that scholars and doctors pay attention to the above issues and carry out research and discussion. 

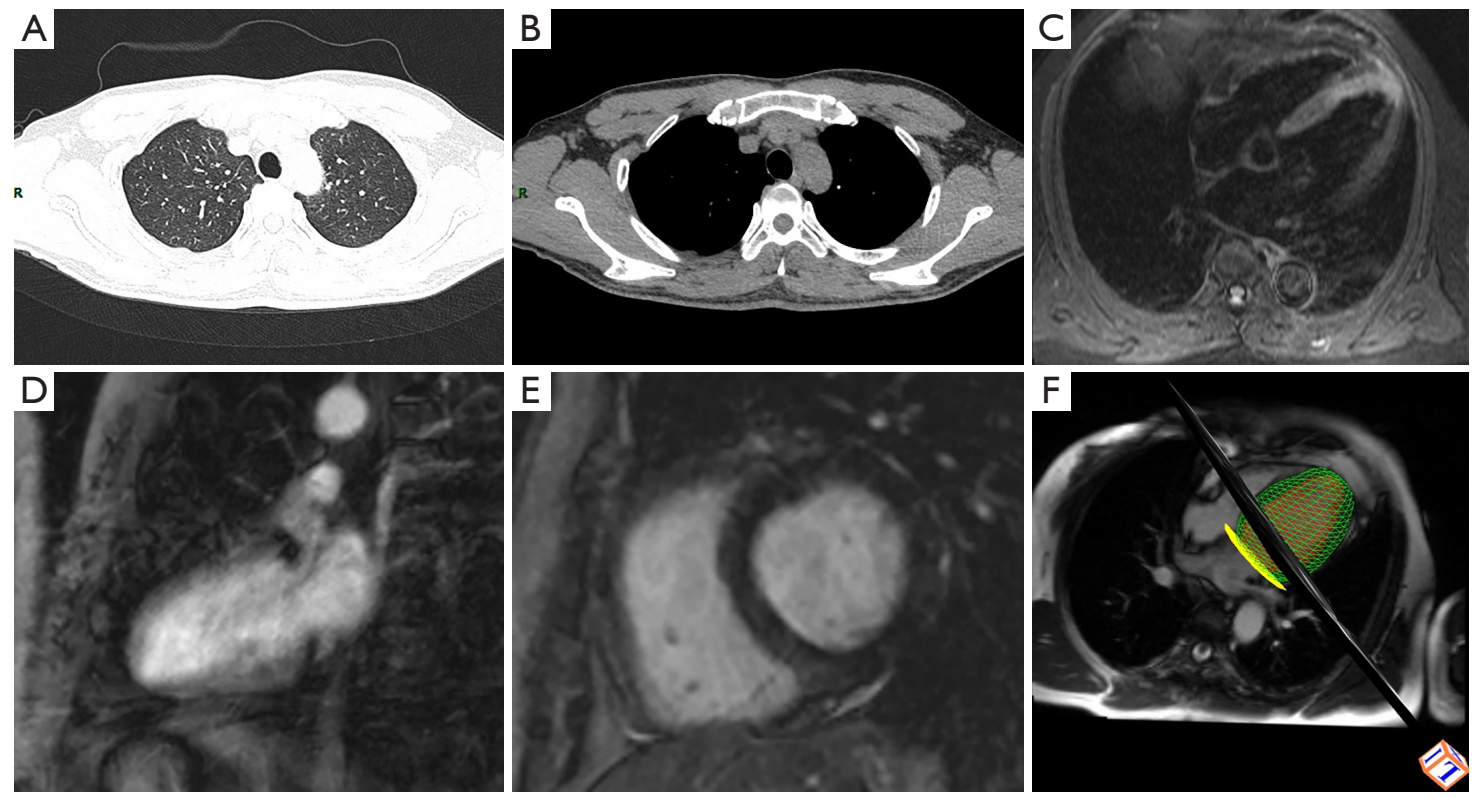

Figure 1 Images of chest CT and cardiac MRI. Shown are the lung window (A), mediastinal window (B) in CT, and T2WI lipid-suppression sequence (C), EGE (D), LGE (E), 4D calculation of left ventricular function (F) in MRI. CT, computed tomography; MRI, magnetic resonance imaging; EGE, early gadolinium enhancement; LGE, late gadolinium enhancement; T2WI, T2-weighted image.

\section{Acknowledgments}

Funding: None.

\section{Footnote}

Conflicts of Interest: All authors have completed the ICMJE uniform disclosure form (available at http://dx.doi. org/10.21037/cdt.2020.03.08). The authors have no conflicts of interest to declare.

Ethical Statement: The authors are accountable for all aspects of the work in ensuring that questions related to the accuracy or integrity of any part of the work are appropriately investigated and resolved.

Open Access Statement: This is an Open Access article distributed in accordance with the Creative Commons Attribution-NonCommercial-NoDerivs 4.0 International License (CC BY-NC-ND 4.0), which permits the noncommercial replication and distribution of the article with the strict proviso that no changes or edits are made and the original work is properly cited (including links to both the formal publication through the relevant DOI and the license). See: https://creativecommons.org/licenses/by-ncnd $/ 4.0 \%$.

\section{References}

1. Zhu N, Zhang D, Wang W, et al. A Novel Coronavirus from Patients with Pneumonia in China, 2019. N Engl J Med. 2020;382:727-33.

2. Li Q, Guan X, Wu P, et al. Early Transmission Dynamics in Wuhan, China, of Novel Coronavirus-Infected Pneumonia. N Engl J Med 2020;382:1199-207.

3. Friedrich MG, Sechtem U, Schulz-Menger J, et al. Cardiovascular magnetic resonance in myocarditis: A JACC White Paper. J Am Coll Cardiol 2009;53:1475-87.

4. Corman V, Bleicker T, Brünink S, et al. Diagnostic detection of Wuhan coronavirus 2019 by real-time RT-PCR. Geneva: World Health Organization, January 13, 2020.

5. Caforio AL, Pankuweit S, Arbustini E, et al. Current state of knowledge on aetiology, diagnosis, management, and therapy of myocarditis: a position statement of the European Society of Cardiology Working Group on Myocardial and Pericardial Diseases. Eur Heart J 2013;34:2636-48, 2648a-2648d.

Cite this article as: Yuan WF, Tang X, Zhao XX. An 'asymptomatic' driver with COVID-19: atypical suspected myocarditis by SARS-CoV-2. Cardiovasc Diagn Ther 2020;10(2):242-243. doi: 10.21037/cdt.2020.03.08 